\title{
Degradation of Soil Fumigants as Affected by Initial Concentration and Temperature
}

\author{
Q. L. Ma, J. Gan,* S. K. Papiernik, J. O. Becker, and S. R. Yates
}

\begin{abstract}
Soil fumigation using shank injection creates high fumigant concentration gradients in soil from the injection point to the soil surface. A temperature gradient also exists along the soil profile. We studied the degradation of methyl isothiocyanate (MITC) and 1,3-dichloropropene (1,3-D) in an Arlington sandy loam (coarse-loamy, mixed, thermic Haplic Durixeralf) at four temperatures and four initial concentrations. We then tested the applicability of first-order, half-order, and second-order kinetics, and the Michaelis-Menten model for describing fumigant degradation as affected by temperature and initial concentration. Overall, none of the models adequately described the degradation of MITC and 1,3-D isomers over the range of the initial concentrations. First-order and half-order kinetics adequately described the degradation of MITC and 1,3-D isomers at each initial concentration, with the correlation coefficients greater than $0.78\left(r^{2}>\right.$ 0.78). However, the derived rate constant was dependent on the initial concentration. The first-order rate constants varied between 6 and $10 \times$ for MITC for the concentration range of 3 to $140 \mathrm{mg} \mathrm{kg}^{-1}$, and between 1.5 and $4 \times$ for 1,3-D isomers for the concentration range of 0.6 to $60 \mathrm{mg} \mathrm{kg}^{-1}$, depending on temperature. For the same initial concentration range, the variation in the half-order rate constants was between 1.4 and 1.7 $\times$ for MITC and between 3.1 and 6.1 $\times$ for 1,3-D isomers, depending on temperature. Second-order kinetics and the Michaelis-Menten model did not satisfactorily describe the degradation at all initial concentrations. The degradation of MITC and 1,3-D was primarily biodegradation, which was affected by temperature between 20 and $40^{\circ} \mathrm{C}$, following the Arrhenius equation $\left(r^{2}>0.74\right)$.
\end{abstract}

$\mathrm{A}^{\mathrm{c}}$ CURATE assessments of the environmental effects of soil fumigants require information on their degradation in the soil, as this is one of the key parameters in determining the fate and transport of chemicals in the environment. Pesticide fate models also need pesticide degradation rates for the fate and exposure assessments. Soil moisture, soil temperature, and chemical concentration may all affect pesticide degradation. The effect of soil moisture on pesticide degradation is frequently described by the power function developed by Walker (1978), and that of soil temperature by the Arrhenius equation:

$$
k=A e^{-\frac{E_{\mathrm{a}}}{R T}}
$$

where $k$ is pesticide degradation rate constant, $A$ is a fitting parameter, $E_{\mathrm{a}}$ is activation energy, and $R$ is the universal gas constant. The effect of concentration on pesticide degradation is often described by first-order kinetics:

$$
C=C_{\mathrm{o}} e^{-k 1 t}
$$

Q.L. Ma, J. Gan, S.R. Yates and S.K. Papiernik, USDA-ARS, Soil Physics and Pesticides Research Unit, George E. Brown Jr. Salinity Lab., Riverside, CA 92507. J.O. Becker, Dep. of Nematology, Univ. of California, Riverside, CA 92521. Received 26 June 2000. *Corresponding author (jgan@UCRAC1.UCR.EDU).

Published in J. Environ. Qual. 30:1278-1286 (2001). where $C$ is chemical concentration $\left(\mathrm{mg} \mathrm{kg}^{-1}\right)$ at time $t$ (h), $C_{\mathrm{o}}$ is initial concentration $\left(\mathrm{mg} \mathrm{kg}^{-1}\right)$, and $k_{1}$ is the first-order rate constant $\left(\mathrm{h}^{-1}\right)$ independent of $C$ and $C_{\mathrm{o}}$. In deriving Eq. [2], it is assumed that only pesticide concentration changes during the course of observation; concentrations of other species, such as degrading microorganisms, remain unchanged. A general equation for $n$ th-order kinetics $(n \neq 1)$ of this type is given by (Sparks, 1989):

$$
\frac{1}{n-1}\left(\frac{1}{C^{n-1}}-\frac{1}{C_{0}^{n-1}}\right)=k_{n} t
$$

where $k_{n}$ is the rate constant for $n$ th-order kinetics, independent of $C$ and $C_{\mathrm{o}}$. For example, for second-order kinetics $(n=2)$, plotting $1 / C$ with respect to time $(t)$ should yield a straight line.

For most pesticides used in agricultural systems, the effect of concentration on pesticide degradation may be reasonably approximated by pseudo first-order kinetics, as these pesticides are applied at rates from less than 1 $\mathrm{kg} \mathrm{ha}^{-1}$ to a few $\mathrm{kg} \mathrm{ha}^{-1}$ (Grover et al., 1997; Wolt, 1997; Kearney and Wauchope, 1998). However, several studies have shown that even in a well-controlled environment, degradation of pesticides in soils did not always follow first-order kinetics (Hamaker et al., 1968; Hance and McKone, 1971; Helweg, 1975; Reffstrup et al., 1998). A difficulty commonly encountered is that when degradation of a pesticide is assessed for a wide range of initial concentrations, degradation at each initial concentration can be reasonably described by firstorder kinetics, but the derived first-order rate constant $\left(k_{1}\right)$ varies with initial concentration, which is contradictory to first-order kinetics. Several other models have been proposed to describe pesticide degradation in soils (Hamaker, 1972, Hamaker and Goring, 1976; Soulas, 1982; Hill and Schaalje, 1985; Schmidt et al., 1985; Alexander and Scow, 1989). Of the models proposed, halforder kinetics and the Michaelis-Menten model have attracted the most attention. The half-order kinetics can be obtained by setting $n=0.5$ in Eq. [3]. The MichaelisMenten model is a variable-order equation, approaching first-order at low concentrations and zero-order at high concentrations (Hamaker et al., 1968). Therefore, theoretically the model may describe pesticide degradation in soils over a range of initial concentrations:

$$
\frac{d C}{d t}=\frac{V_{\mathrm{m}} C}{K_{\mathrm{m}}+C}
$$

where $V_{\mathrm{m}}\left(\mathrm{h}^{-1}\right)$ is the maximum rate of pesticide degradation and $K_{\mathrm{m}}\left(\mathrm{mg} \mathrm{kg}^{-1}\right)$ is the Michaelis-Menten constant. Other variables are as defined previously. The

Abbreviations: 1,3-D, 1,3-dichloropropene; GC, gas chromatography; MITC, methyl isothiocyanate. 
integral form of the equation after an appropriate arrangement is:

$$
\frac{C_{0}-C}{t}+K_{\mathrm{m}} \frac{\ln \frac{C_{0}}{C}}{t}=V_{\mathrm{m}}
$$

If degradation follows the Michaelis-Menten equation (Eq. [5]), the plot of

$$
C_{\mathrm{o}}-C / t \text { against } \frac{\ln \frac{C_{\mathrm{o}}}{C}}{t}
$$

should yield a straight line with slope of $K_{\mathrm{m}}$ and intercept of $V_{\mathrm{m}}$.

Compared with other pesticides, soil fumigants as a class have notable differences in their biocidal activities and methods and rates of application. For example, soil fumigants are normally injected into the soil at certain depth at application rates of $\sim 250 \mathrm{~kg} \mathrm{ha}{ }^{-1}$, which is approximately two orders of magnitude higher than the application rates of most other pesticides. Higher application rates create higher initial concentrations at the injection points that may reduce the populations of degrading microorganisms (Parr, 1974; Ladd et al., 1976; Macalady et al., 1998). At locations away from the injection points, fumigant concentrations are much lower, and the inhibitory effect of the chemicals on degrading microorganisms may be less significant. Because some fumigants degrade largely by biodegradation $(\mathrm{Tu}, 1972$; Smelt et al., 1989; Gan et al., 1999), it is expected that concentration may have a significant effect on the degradation rate of fumigants in soils. However, this hypothesis is yet to be validated.

We studied the degradation of methyl isothiocyanate (MITC) and two isomers of 1,3-dichloropropene (1,3-D) in an Arlington sandy loam soil under well-controlled conditions using four initial concentrations at four temperatures. We then tested the applicability of first-order, half-order, and second-order kinetics, and the Michaelis-Menten model for describing the degradation of the fumigants as affected by temperature and initial concentration. We used MITC and 1,3-D in this study because of their high usage, which is expected to further expand when methyl bromide is phased out by the year 2005 .

\section{MATERIALS AND METHODS}

\section{Soil and Chemicals}

The soil was an Arlington sandy loam taken from the top $20 \mathrm{~cm}$ in a field at the University of California Agricultural Experiment Station at Riverside, about $1 \mathrm{~km}$ southeast of the campus. The soil had a $\mathrm{pH}$ of 7.4 and consisted of $64 \%$ sand, $7 \%$ clay, and $0.92 \%$ organic matter. Fresh soil was passed through a $2-\mathrm{mm}$ sieve and stored at room temperature before use. Technical standards of MITC (99\%) and 1,3-D [48\% $(E)$ and $49 \%(Z)$-isomer] were purchased from Chem Service (Bellefonte, NJ). The chemicals were dissolved in ultrapure water just before use and a range of concentrations was prepared for the study.

\section{Incubation Experiments at Different Temperatures and Initial Concentrations}

Ten grams (dry weight) of fresh soil was weighed into 20$\mathrm{mL}$ vials after adjustment of soil water content to $5 \%$ by weight. These samples were spiked with $0.5 \mathrm{~mL}$ of MITC solution to result in initial concentrations of 3.31, 24.35, 56.01, and $142.70 \mathrm{mg} \mathrm{kg}^{-1}$, respectively. The lowest concentration (3.31 $\mathrm{mg} \mathrm{kg}^{-1}$ ) corresponds to $7 \%$ of the recommended field application rate $\left(250 \mathrm{~kg} \mathrm{ha}^{-1}\right)$, assuming a uniform distribution in the top $30 \mathrm{~cm}$ of soil; while the highest concentration (142.70 $\mathrm{mg} \mathrm{kg}^{-1}$ ) corresponds to 2.8 times the recommended field application rate. This concentration range is within that expected in the field when MITC is applied by shank injection. These vials were capped immediately with aluminum seals and Teflon-faced butyl rubber septa and then transferred into temperature-controlled rooms or incubators at 20,30,35, and $40^{\circ} \mathrm{C}$, with temperature variation less than $0.5^{\circ} \mathrm{C}$.

Triplicate vials were taken at different time intervals and immediately stored at $-20^{\circ} \mathrm{C}$ until analysis. For extraction, the sample vials were decapped while still frozen, and after addition of $10 \mathrm{~g}$ of anhydrous sodium sulfate and $10 \mathrm{~mL}$ of ethyl acetate, the vials were immediately recapped. The vials were placed on a shaker for $1 \mathrm{~h}$ at $5000 \mathrm{rph}$, then $1.5 \mathrm{~mL}$ of the supernatant from each vial was transferred into a gas chromatography (GC) vial. Preliminary studies showed that this extraction method gave an average recovery of $95 \%$ for MITC. The concentration of MITC was determined by a HP (Palo Alto, CA) 6890 GC equipped with a microelectron capture detector $(\mu \mathrm{ECD})$. The GC conditions were $30-\mathrm{m} \times 0.25$ $\mathrm{mm} \times 1.4-\mu \mathrm{m}$ RTX-624 capillary column (Restek Co., Bellefonte, PA) at a flow rate of $1.3 \mathrm{~mL} \mathrm{~min}^{-1}$. The starting oven temperature was $50^{\circ} \mathrm{C}$ and then the temperature was increased at $15^{\circ} \mathrm{C} \mathrm{min}{ }^{-1}$ until it reached $125^{\circ} \mathrm{C}$. The inlet temperature was $240^{\circ} \mathrm{C}$ and the detector temperature was $300^{\circ} \mathrm{C}$.

Additional experiments were conducted to determine whether the degradation of MITC was primarily by chemical or by microbial degradation by comparing degradation in sterilized and nonsterilized soils at low (3.34 $\left.\mathrm{mg} \mathrm{kg}^{-1}\right)$ and high (142.58 $\mathrm{mg} \mathrm{kg}^{-1}$ ) initial concentrations. The sterilized soil was obtained by autoclaving the soil twice at $121^{\circ} \mathrm{C}$, each for 60 min, with a $24-h$ interval. Sterilized water was added into the sterilized soil samples to bring soil water content to $5 \%$ by weight. Comparisons of MITC degradation in sterilized and nonsterilized soils can also reveal whether there was an inhibitory effect by the chemical on degrading microorganisms at elevated concentrations.

Similar experiments and analyses were carried out for 1,3-D isomers using initial concentrations of $0.60,9.95,14.18$, and $58.82 \mathrm{mg} \mathrm{kg}^{-1}$ for the $(E)$-isomer and $0.65,9.98,15.27$, and $60.33 \mathrm{mg} \mathrm{kg}^{-1}$ for the $(Z)$-isomer. The $1,3-\mathrm{D}$ isomers were extracted from the soil using ethyl acetate and their concentrations determined by GC with the same capillary column as for MITC. The gas flow rate was set at $1.2 \mathrm{~mL} \mathrm{~min}{ }^{-1}$. The starting oven temperature was $70^{\circ} \mathrm{C}$ and then the temperature was increased at a rate of $20^{\circ} \mathrm{C} \mathrm{min}{ }^{-1}$ until it reached the final temperature of $140^{\circ} \mathrm{C}$. The inlet temperature was $230^{\circ} \mathrm{C}$ and the detector temperature was $280^{\circ} \mathrm{C}$. Under these conditions, the recoveries were 93 and $89 \%$ for $(E)$ - and $(Z)-1,3-\mathrm{D}$ isomers, respectively, at an initial concentration of $9.95 \mathrm{mg} \mathrm{kg}^{-1}$. Degradation of 1,3-D isomers in sterilized and nonsterilized soils was also compared at initial concentrations of 1.19 and $1.97 \mathrm{mg} \mathrm{kg}^{-1}$ for the $(E)$ - and $(Z)$-isomer, respectively.

The degradation data thus obtained were fitted to firstorder, half-order, and second-order kinetics, and the Michaelis-Menten model using a least-square regression method. The adjusted coefficient of fitting $\left(r^{2}\right)$ was used to evaluate the 
Table 1. The first-order $\left(k_{1}\right)$ and the half-order $\left(k_{0.5}\right)$ degradation rate constants of methyl isothiocyanate (MITC) at different temperatures and initial concentrations.

\begin{tabular}{|c|c|c|c|c|}
\hline \multirow[b]{2}{*}{ Initial concentration } & \multicolumn{4}{|c|}{ Temperature $\left({ }^{\circ} \mathrm{C}\right)$} \\
\hline & 20 & 30 & 35 & 40 \\
\hline \multicolumn{5}{|c|}{$-k_{1} \dagger \times 10^{2}\left(\mathrm{~h}^{-1}\right)$} \\
\hline 3.31 & $2.08 \pm 0.21(0.99) \ddagger$ & $4.54 \pm 0.23(0.99)$ & $4.80 \pm 0.35(0.99)$ & $5.14 \pm 0.18(0.99)$ \\
\hline 24.75 & $0.39 \pm 0.04(0.97)$ & $0.90 \pm 0.06(0.99)$ & $1.18 \pm 0.04(0.99)$ & $1.65 \pm 0.10(0.99)$ \\
\hline 56.01 & $0.30 \pm 0.04(0.97)$ & $0.70 \pm 0.07(0.97)$ & $0.85 \pm 0.04(0.99)$ & $1.14 \pm 0.04(0.99)$ \\
\hline \multirow[t]{2}{*}{142.70} & $0.23 \pm 0.03(0.93)$ & $0.45 \pm 0.04(0.97)$ & $0.57 \pm 0.04(0.98)$ & $0.86 \pm 0.07(0.98)$ \\
\hline & \multicolumn{4}{|c|}{$-k_{0.5} \dagger \times 10^{2}\left(\mathrm{~h}^{-1}\right)$} \\
\hline 3.31 & $1.88 \pm 0.15(0.88)$ & $5.24 \pm 0.20(0.98)$ & $5.72 \pm 0.21(0.98)$ & $5.78 \pm 0.28(0.97)$ \\
\hline 24.75 & $1.68 \pm 0.07(0.97)$ & $3.10 \pm 0.14(0.96)$ & $3.74 \pm 0.16(0.96)$ & $4.36 \pm 0.26(0.93)$ \\
\hline 56.01 & $1.90 \pm 0.12(0.93)$ & $3.70 \pm 0.21(0.94)$ & $4.48 \pm 0.16(0.98)$ & $5.44 \pm 0.20(0.97)$ \\
\hline 142.70 & $2.38 \pm 0.15(0.92)$ & $4.24 \pm 0.23(0.95)$ & $5.36 \pm 0.20(0.97)$ & $7.06 \pm 0.32(0.96)$ \\
\hline
\end{tabular}

$\dagger$ The first-order $\left(k_{1}\right)$ and the half-order $\left(k_{0.5}\right)$ degradation rate constants were obtained by fitting measured concentrations at different times to first-order and half-order kinetics respectively using the least-square-error fitting procedure.

$\ddagger$ Mean \pm standard error. Data in parentheses are coefficients of fitting (adjusted $\boldsymbol{r}^{2}$ ).

goodness of fit. All statistical analyses were performed at the 0.05 significance level unless otherwise specified.

\section{RESULTS AND DISCUSSION \\ Degradation of MITC and 1,3-D Isomers as Affected by Concentration}

Degradation of MITC at each initial concentration can be described by first-order kinetics $\left(r^{2}>0.93\right)$ (Table 1). Only data at $20^{\circ} \mathrm{C}$ are shown in Fig. 1 , as data at other temperatures followed a similar pattern. There was a ninefold difference in the derived first-order degradation rate constants between the lowest and the highest concentrations at $20^{\circ} \mathrm{C}$ (Table 1). A general trend existed that the derived first-order rate constant decreased with increasing initial concentration (Fig. 2), which is contradictory to the basic assumptions of firstorder kinetics. Hance and McKone (1971) reported a similar correlation between initial concentration and first-order rate constant for atrazine, linuron, and piclo- ram. Analyses of MITC degradation curves at 30, 35, and $40^{\circ} \mathrm{C}$ show similar results (Table 1 ). These results demonstrate that a single first-order rate constant cannot adequately describe the degradation of MITC at all initial concentrations, even though the degradation at each initial concentration can be fitted to first-order kinetics $\left(r^{2}>0.93\right)$.

Degradation of $(E)-1,3-D$ isomer at each initial concentration can be also described by first-order kinetics $\left(r^{2}>0.78\right)$ (Table 2). As for MITC, only degradation curves at $20^{\circ} \mathrm{C}$ are shown (Fig. 3). Fits were generally good $\left(r^{2}>0.95\right)$ except at the highest initial concentration (Table 2). The derived first-order degradation rate constants of $(E)-1,3-\mathrm{D}$ at an initial concentration of $0.60 \mathrm{mg} \mathrm{kg}^{-1}$ were 2.1 to 4.1 times those at an initial concentration of $58.82 \mathrm{mg} \mathrm{kg}^{-1}$, depending on temperature (Table 2). There existed a general trend that the derived first-order rate constant decreased with increasing initial concentration. Likewise, degradation of the ( $Z$ )-1,3-D isomer at each initial concentration can be

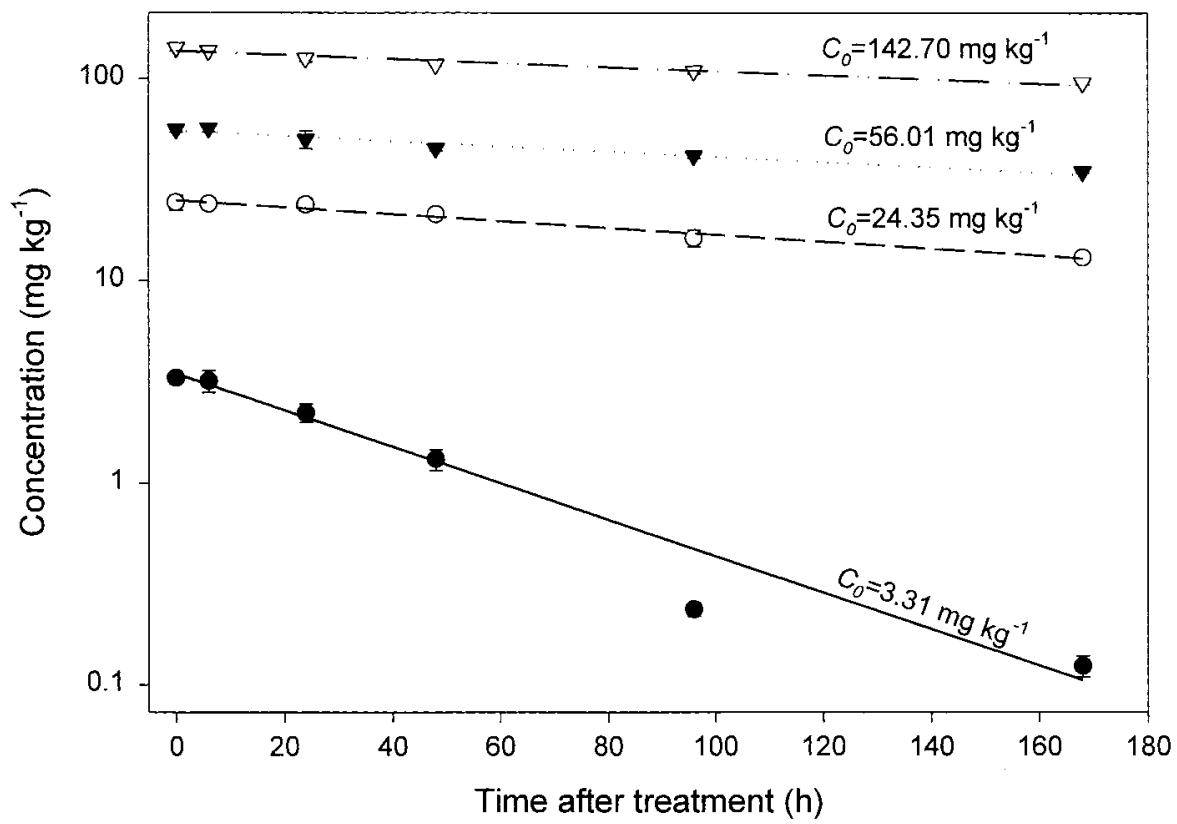

Fig. 1. Degradation of methyl isothiocyanate (MITC) in Arlington sandy loam at different initial concentrations at $20^{\circ} \mathrm{C}$. The points are the means of three measurements $( \pm$ standard errors) and the curves are first-order fits. 


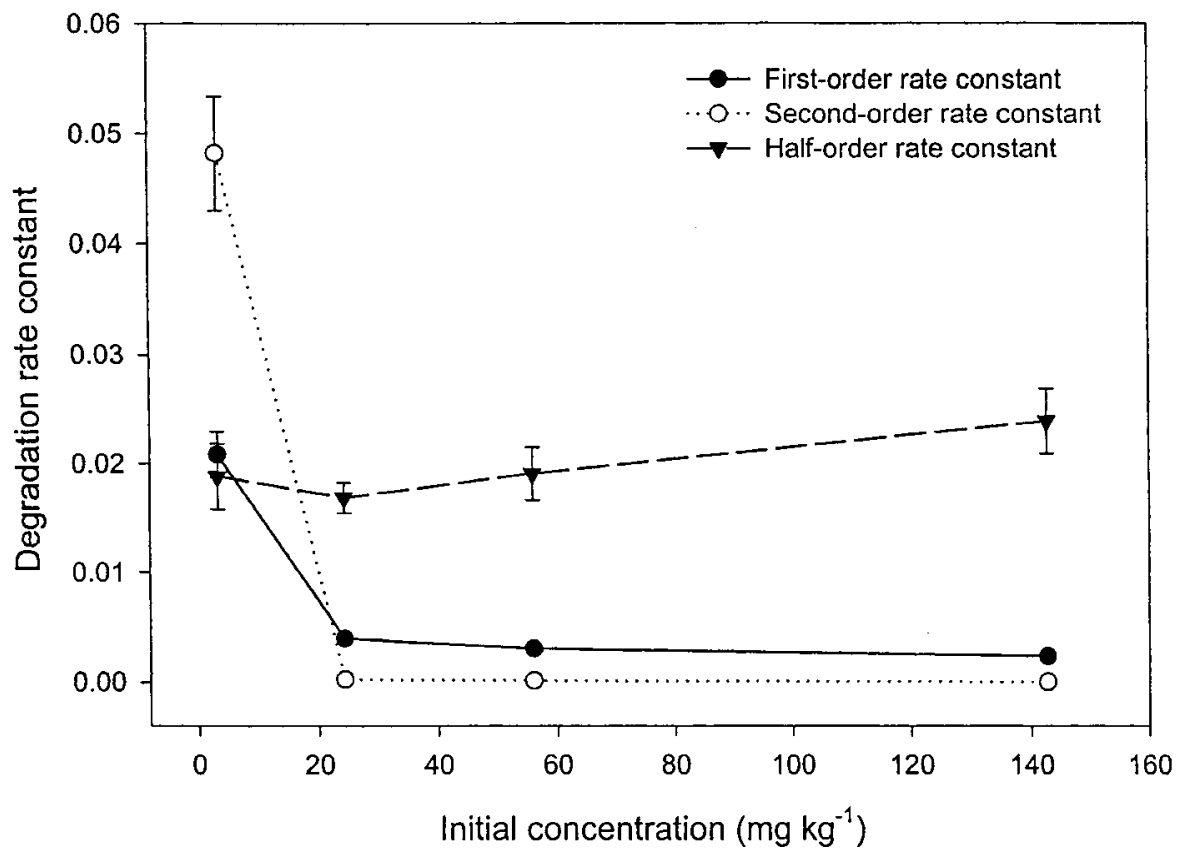

Fig. 2. Correlation between initial concentration and derived degradation rate constant for methyl isothiocyanate (MITC) in Arlington sandy loam at $20^{\circ} \mathrm{C}$. The points are mean $( \pm$ standard errors) degradation rate constants obtained by fitting to respective kinetics.

also fitted to first-order kinetics $\left(r^{2}>0.85\right)$ (Table 2). Good fits $\left(r^{2}>0.96\right)$ were obtained at lower initial concentrations, as was observed for the $(E)-1,3-\mathrm{D}$ isomer (Table 2). The first-order degradation rate constants of $(Z)-1,3-\mathrm{D}$ at an initial concentration of 0.65 $\mathrm{mg} \mathrm{kg}{ }^{-1}$ were 1.5 to 2.9 times those at an initial concentration of $60.33 \mathrm{mg} \mathrm{kg} \mathrm{m}^{-1}$, depending on temperature (Table 2). Thus, one single first-order rate constant cannot adequately describe the degradation of each isomer over the entire concentration range used in the study (Table 2).

These results demonstrate that the derived first-order rate constants are not concentration-independent, as the first-order kinetics implies, but are dependent on the initial chemical concentration. Therefore, the assumption in some integrated simulation models that degradation of pesticides in soils can be represented by a single first-order rate constant may be invalid. Large differ- ences in the first-order rate constants for MITC (Table 1) and 1,3-D isomers (Table 2) at different initial concentrations suggest that significant errors can be introduced in model predictions of the chemical fate and exposure. In studying the effect of the first-order rate constant on pesticide leaching predictions, Boesten and van der Linden (1991) demonstrated that a $2 \times$ variation in the first-order degradation rate constant led to $10 \times$ changes in predicted pesticide leaching. While the firstorder degradation rate constants or half-lives are often used in the pesticide literature, either because of simplicity, convenience, or apparent validity, care must be taken to verify their accuracy in representing pesticide degradation in soils. Otherwise, attempts to accurately predict chemical concentration distributions in the soil profile may fail.

The applicability of second-order and half-order kinetics and the Michaelis-Menten model was then tested

Table 2. The first-order degradation rate constants $\left(k_{1}\right)$ of $(E)$ - and $(Z)$-1,3-dichloropropene (1,3-D) isomers at different temperatures and initial concentrations.

\begin{tabular}{|c|c|c|c|c|}
\hline \multirow[b]{2}{*}{ Initial concentration } & \multicolumn{4}{|c|}{ Temperature $\left({ }^{\circ} \mathbf{C}\right)$} \\
\hline & 20 & 30 & 35 & 40 \\
\hline \multirow[t]{2}{*}{$\mathrm{mg} \mathrm{kg}^{-1}$} & \multirow{2}{*}{\multicolumn{4}{|c|}{$\begin{array}{c}-k_{1} \dagger \times 10^{2}\left(h^{-1}\right)- \\
\underline{(E)-1,3-\mathrm{D}}\end{array}$}} \\
\hline & & & & \\
\hline 0.60 & $1.07 \pm 0.10(0.98)+$ & $2.20 \pm 0.17(0.99)$ & $2.82 \pm 0.14(0.99)$ & $3.43 \pm 0.38(0.98)$ \\
\hline 9.55 & $0.56 \pm 0.06(0.96)$ & $0.91 \pm 0.05(0.99)$ & $1.43 \pm 0.10(0.99)$ & $1.84 \pm 0.09(0.99)$ \\
\hline 14.18 & $0.40 \pm 0.04(0.95)$ & $0.87 \pm 0.08(0.98)$ & $1.01 \pm 0.10(0.98)$ & $1.58 \pm 0.10(0.99)$ \\
\hline \multirow[t]{2}{*}{58.82} & $\mathbf{0 . 2 6} \pm \mathbf{0 . 0 3}(\mathbf{0 . 9 3})$ & $0.93 \pm 0.15(0.92)$ & $0.93 \pm 0.28(0.78)$ & $1.64 \pm 0.26(0.95)$ \\
\hline & \multicolumn{4}{|c|}{$\underline{(Z)-1,3-D}$} \\
\hline 0.65 & $\mathbf{0 . 8 3} \pm 0.08(0.97)$ & $1.89 \pm 0.13(0.99)$ & $2.48 \pm 0.14(0.99)$ & $3.17 \pm 0.28(0.99)$ \\
\hline 9.98 & $0.57 \pm 0.06(0.96)$ & $1.00 \pm 0.04(0.99)$ & $1.52 \pm 0.04(0.99)$ & $2.20 \pm 0.10(0.99)$ \\
\hline 15.27 & $\mathbf{0 . 4 2} \pm \mathbf{0 . 0 8}(\mathbf{0 . 8 5})$ & $1.01 \pm 0.07(0.99)$ & $1.22 \pm 0.08(0.99)$ & $2.01 \pm 0.12(0.99)$ \\
\hline 60.33 & $\mathbf{0 . 2 8} \pm \mathbf{0 . 0 3}(\mathbf{0 . 9 4 )}$ & $1.07 \pm 0.16(0.94)$ & $1.27 \pm 0.35(0.94)$ & $2.17 \pm 0.30(0.97)$ \\
\hline
\end{tabular}

$\dagger$ The first-order degradation rate constants were obtained by fitting measured concentrations at different times to first-order kinetics using the leastsquare-error fitting procedure.

$\$$ Mean \pm standard error. Data in parentheses are coefficients of fitting (adjusted $\boldsymbol{r}^{2}$ ). 


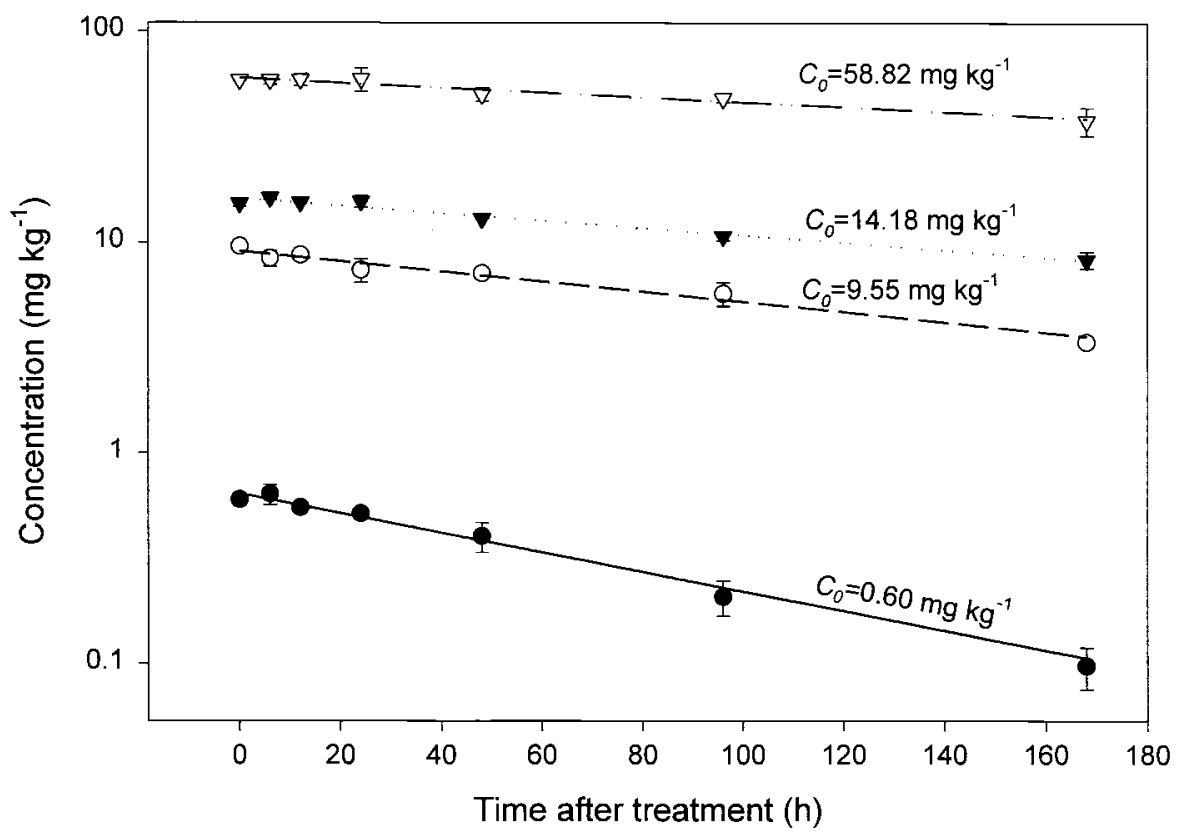

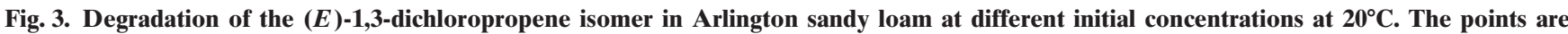
mean of three measurements ( \pm standard errors) and the curves are first-order fits.

for MITC and 1,3-D isomers at all temperatures. Plotting the inverse of the measured concentration $(1 / C)$ with respect to time $(t)$ at different initial concentrations did not yield a constant slope (second-order rate constant) for MITC (Fig. 2) or 1,3-D isomers (not shown). The fits were generally not as good as those for firstorder kinetics $\left(r^{2}>0.76\right)$, although better fits were obtained at higher initial concentrations $\left(r^{2}>0.91\right)$. Overall, the derived second-order degradation rate constant decreased with increasing initial concentration (Fig. 2), as is for the first-order rate constant. The maximum differences in the second-order rate constants were on the order of $1000 \times$ between the lowest and highest initial concentrations. Therefore, degradation of MITC and 1,3-D isomers did not follow second-order kinetics.

Degradation of MITC at each initial concentration can be fitted to half-order kinetics (Table 1) $\left(r^{2}>0.88\right)$. The resulting half-order rate constants varied with initial concentrations, but to much less of an extent than the first-order rate constants (Table 1), with the maximum differences varying between $1.4 \times$ and $1.7 \times$, depending on temperature. Hamaker et al. (1968) also reported that the half-order rate constant of 4-amino-3,5,6-trichloropicolinic acid was less affected by initial concentration than the first-order rate constant. The fitted halforder rate constants for each 1,3-D isomer increased with increasing initial concentration, with the maximum differences varying between $3.1 \times$ and $4.2 \times$ for the $(E)$ isomer and between $3.8 \times$ and $6.1 \times$ for the $(Z)$-isomer, depending on temperature (Table 3). Therefore, the fitted half-order rate constants for 1,3-D isomers varied more significantly with initial concentration than the first-order rate constants. Thus, one single half-order rate constant cannot adequately represent the degradation of MITC and 1,3-D isomers in the soil over a range of initial concentrations.

The Michaelis-Menten model did not satisfactorily describe the degradation of MITC and 1,3-D isomers at all initial concentrations (not shown). In some cases, the fits were poor and the fitted parameter values $\left(K_{\mathrm{m}}\right.$, $V_{\mathrm{m}}$ ) were negative, suggesting that the Michaelis-Menten model does not apply. Overall, first-order and halforder kinetics fit the data better than second-order kinetics and the Michaelis-Menten model. However, none of the models tested satisfactorily described the degradation of MITC and 1,3-D isomers over a range of initial concentrations.

Degradation of MITC in sterilized soil was compared with that in nonsterilized soil at $20^{\circ} \mathrm{C}$ (Fig. 4) because high temperature itself $\left(>40^{\circ} \mathrm{C}\right)$ can suppress microorganism activities (Gan et al., 1999). We used the lowest $\left(3.34 \mathrm{mg} \mathrm{kg}^{-1}\right)$ and the highest $\left(142.58 \mathrm{mg} \mathrm{kg}^{-1}\right)$ concentrations for this comparison. During a 6-d incubation period at an initial concentration of $3.34 \mathrm{mg} \mathrm{kg}^{-1}$, degradation of MITC in both sterilized and nonsterilized soils can be fitted to first-order kinetics $\left(r^{2}>0.91\right)$ (Fig. 4). The first-order rate constant in nonsterilized soil was 10 times larger than that in sterilized soil, suggesting that the major dissipation pathway for MITC in the soil may be biodegradation (91\%). This supports earlier studies by Smelt et al. (1989) and Gan et al. (1999). Concentrations of MITC in sterilized soil were significantly larger than those in nonsterilized soil over the entire period of observations except at the beginning (Fig. 4), which suggests that MITC might not have posed significant inhibitory effects on degrading microorganisms at this concentration level. Alternatively, inhibitory effects might have occurred but the inhibited populations recovered before the first sampling interval $(6 \mathrm{~h}$ after treatment). In studies of the effects of four nematocides on microorganism activities in a loamy sand soil, $\mathrm{Tu}$ (1972) observed that both bacterial and fungal populations initially decreased at low nematocide application rates, but the populations recovered rapidly to levels 
Table 3. The half-order degradation rate constants $\left(k_{0.5}\right)$ of $(E)$ - and $(Z)$-1,3-dichloropropene (1,3-D) isomers at different temperatures and initial concentrations.

\begin{tabular}{|c|c|c|c|c|}
\hline \multirow[b]{2}{*}{ Initial concentration } & \multicolumn{4}{|c|}{ Temperature $\left({ }^{\circ} \mathrm{C}\right)$} \\
\hline & 20 & 30 & 35 & 40 \\
\hline $\mathrm{mg} \mathrm{kg}^{-1}$ & \multicolumn{4}{|c|}{$\begin{array}{c}-k_{0.5} \dagger \times 10^{2}\left(h^{-1}\right) \\
(E)-1,3-D\end{array}$} \\
\hline \begin{tabular}{l|l|}
0.60 \\
9.55 \\
14.18 \\
58.82
\end{tabular} & $\begin{array}{l}0.60 \pm 0.04(0.98) \ddagger \\
1.36 \pm 0.10(0.97) \\
1.38 \pm 0.12(0.96) \\
1.86 \pm 0.18(0.94)\end{array}$ & $\begin{array}{l}1.18 \pm 0.06(0.99) \\
2.02 \pm 0.06(0.99) \\
2.26 \pm 0.24(0.94) \\
4.96 \pm 0.76(0.87)\end{array}$ & $\begin{array}{l}1.32 \pm 0.08(0.98) \\
2.44 \pm 0.24(0.94) \\
2.80 \pm 0.16(0.98) \\
4.48 \pm 0.82(0.82)\end{array}$ & $\begin{array}{l}192 \pm 0.18(0.97) \\
2.80 \pm 0.28(0.95) \\
3.10 \pm 0.34(0.94) \\
6.40 \pm 86(0.90)\end{array}$ \\
\hline 58.82 & \multicolumn{4}{|c|}{ (Z)-1,3-D } \\
\hline $\begin{array}{l}0.65 \\
9.98 \\
15.27 \\
60.33\end{array}$ & $\begin{array}{l}0.52 \pm 0.04(0.98) \\
1.42 \pm 0.10(0.97) \\
\mathbf{1 . 4 8} \pm \mathbf{0 . 2 2}(\mathbf{0 . 8 9}) \\
\mathbf{2 . 0 0} \pm \mathbf{0 . 1 8}(\mathbf{0 . 9 5 )}\end{array}$ & $\begin{array}{l}0.90 \pm 0.06(0.97) \\
2.20 \pm 0.08(0.99) \\
2.58 \pm 0.26(0.95) \\
5.52 \pm 0.78(0.89)\end{array}$ & $\begin{array}{l}1.30 \pm 0.06(0.99) \\
2.64 \pm 0.22(0.96) \\
3.18 \pm 0.20(0.98) \\
5.32 \pm 0.88(0.85)\end{array}$ & $\begin{array}{l}1.46 \pm 0.12(0.99) \\
3.02 \pm 0.36(0.92) \\
3.76 \pm 0.46(0.92) \\
7.16 \pm 1.04(0.88)\end{array}$ \\
\hline
\end{tabular}

$\dagger$ The half-order degradation rate constants were obtained by fitting measured concentrations at different times to half-order kinetics using the leastsquare-error fitting procedure.

+ Mean \pm standard error. Data in parentheses are coefficients of fitting (adjusted $\left.r^{2}\right)$.

similar to those in the control. At an initial concentration of $142.58 \mathrm{mg} \mathrm{kg}^{-1}$, degradation of MITC in both sterilized and nonsterilized soils can be fitted to firstorder kinetics $\left(r^{2}>0.90\right)$. The first-order degradation rate constant of MITC in nonsterilized soil was only 1.8 times that in sterilized soil. Moreover, during the first $2 \mathrm{~d}$ after treatment, concentrations of MITC in both sterilized and nonsterilized soils were nearly the same (Fig. 4), which may indicate that MITC posed inhibitory effects on degrading microorganisms. This 2-d period may be also an adaptation period for microorganisms to degrade MITC. With time the differences in MITC concentrations increased between sterilized and nonsterilized soils (Fig. 4). Pronounced inhibitory effects of fumigants including MITC on soil microorganisms were also observed in previous studies (Tu, 1972; Macalady et al., 1998) and were associated with marked inhibitions of nitrification and soil respiration (Parr, 1974). The inhibitory effect imposed at a higher initial concentration would cause less relative percentage loss of MITC than that at a lower initial concentration at which the inhibitory effect was unnoticeable, resulting in a smaller first-order degradation rate constant $\left(k_{1}\right)$ at a higher initial concentration. However, this does not translate into a smaller amount of MITC degraded at a higher initial concentration because $k_{1}$ is calculated on a relative basis (Eq. [1]).

Degradation of 1,3-D isomers in both sterilized and nonsterilized soils was examined at a low initial concentration at $20^{\circ} \mathrm{C}$ (Fig. 5). During an 8-d incubation period, degradation of both isomers in both soils can be fitted to first-order kinetics $\left(r^{2}>0.95\right)$. The resulting rate constants in nonsterilized soil were 3.3 and 2.1 times those in sterilized soil for the $(E)$-isomer and the $(Z)$ isomer, respectively. This suggests that biodegradation was the major dissipation pathway for 1,3-D isomers

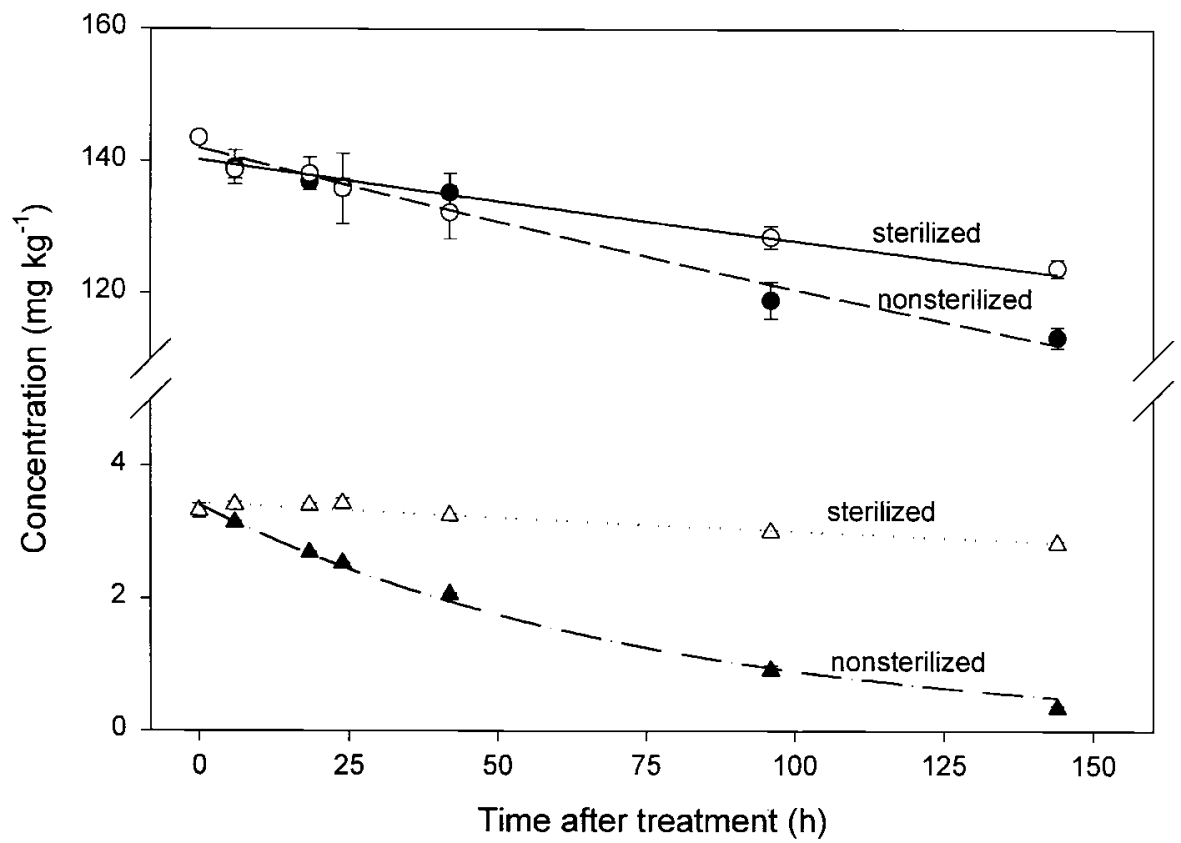

Fig. 4. Comparison of methyl isothiocyanate (MITC) degradation in sterilized and nonsterilized soils at $20^{\circ} \mathrm{C}$. The points are the means of three measurements ( \pm standard errors) and the curves are first-order fits. 


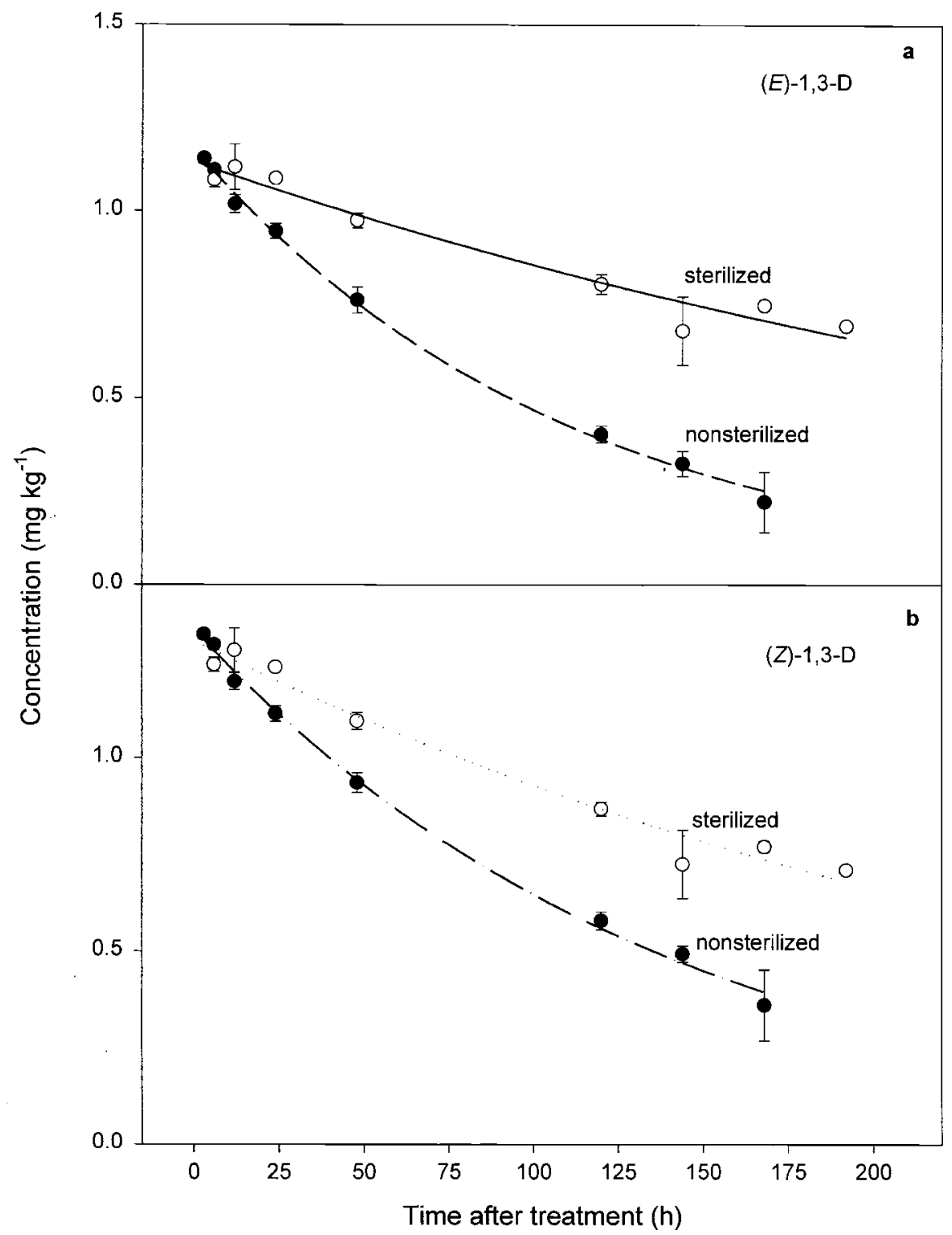

Fig. 5. Comparison of $(E)$ - and $(Z)-1,3-$ dichloropropene isomer degradation in sterilized and nonsterilized soils at $20^{\circ} \mathrm{C}$. The points are the means of three measurements ( \pm standard errors) and the curves are first-order fits.

(68 to $76 \%$ ). The differences in degradation rate constants of 1,3-D isomers between sterilized and nonsterilized soils are smaller than that of MITC at an initial concentration of $3.34 \mathrm{mg} \mathrm{kg}^{-1}$ (10× difference), suggesting that more abiotic degradation might have been involved in degrading 1,3-D isomers (24 to $32 \%$ ) than in degrading MITC (9\%).

\section{Degradation of MITC and 1,3-D Isomers as Affected by Temperature}

A common approach to evaluate the effect of temperature on pesticide degradation is to compare the firstorder rate constants $\left(k_{1}\right)$ obtained at different temperatures. As $k_{1}$ is usually obtained only at one initial concentration, the effect of initial concentration is thus ignored. We explored two cases. In the first case, we applied the derived $k_{1}$ for the evaluations, as is com- monly done. In the second case, we used the half-order rate constant $\left(k_{0.5}\right)$ for the evaluations since $k_{0.5}$ was relatively less dependent on the initial concentration for MITC.

At the same initial concentration, the $k_{1}$ of MITC (Table 1) changed exponentially with temperature between 20 and $40^{\circ} \mathrm{C}$, and followed the Arrhenius equation $\left(r^{2} \geq 0.79\right)$ (Table 4). The poor fit $\left(r^{2}=0.79\right)$ was obtained at the lowest initial concentration, whereas better fits were obtained at higher initial concentrations $\left(r^{2} \geq 0.97\right)$ (Table 4). Presumably more biodegradation was involved in degrading MITC at low initial concentrations, while the Arrhenius equation was primarily developed for describing chemical reactions in solution. There was no significant difference in activation energy at different initial concentrations except at the lowest initial concentration at which the activation energy was significantly smaller than that at other initial concentra- 
Table 4. Degradation activation energy $\left(E_{\mathrm{a}}\right)$ of methyl isothiocyanate $(\mathrm{MITC})$ and $(E)$ - and $(Z)$-1,3-dichloropropene (1,3-D) isomers calculated using the first-order $\left(k_{1}\right)$ and the half-order $\left(k_{0.5}\right)$ rate constants between 20 and $40^{\circ} \mathrm{C}$.

\begin{tabular}{|c|c|c|c|}
\hline \multirow[b]{3}{*}{ Initial concentration } & \multicolumn{3}{|c|}{$\boldsymbol{E}_{\mathrm{a}}$} \\
\hline & \multicolumn{3}{|c|}{ Fumigants } \\
\hline & MITC & $(E)-1,3-D$ & $(Z)-1,3-\mathrm{D}$ \\
\hline \multirow[t]{2}{*}{$\mathrm{mg} \mathrm{kg}^{-1}$} & 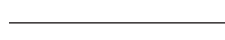 & $-\mathrm{kJ} \mathrm{mol}^{-1}$ & \\
\hline & \multicolumn{3}{|c|}{ Calculated using $k_{1}$} \\
\hline $\mathrm{C} 1 \dagger$ & $34.9 \pm 9.9(0.79) \div$ & $45.1 \pm 3.8(0.98)$ & $51.6 \pm 4.0(0.98)$ \\
\hline $\mathbf{C} 2 \dagger$ & $50.6 \pm 3.4(0.97)$ & $46.2 \pm 4.4(0.97)$ & $51.3 \pm 4.0(0.98)$ \\
\hline $\mathbf{C} 3 \dagger$ & $50.4 \pm 5.3(0.97)$ & $50.5 \pm 4.8(0.97)$ & $57.8 \pm 4.9(0.98)$ \\
\hline $\mathbf{C 4} \dagger$ & $48.9 \pm 2.2(0.99)$ & $67.3 \pm 11.9(0.91)$ & $76.4 \pm 9.4(0.96)$ \\
\hline \multirow[t]{2}{*}{ Average } & $46.2 \pm 7.5$ & $52.3 \pm 10.3$ & $59.3 \pm 11.8$ \\
\hline & \multicolumn{3}{|c|}{ Calculated using $\boldsymbol{k}_{0.5}$} \\
\hline $\mathrm{C1} \dagger$ & $44.7 \pm 14.3(0.74)$ & $43.4 \pm 4.4(0.98)$ & $41.6 \pm 3.9(0.97)$ \\
\hline $\mathrm{C} 2 \dagger$ & $41.8 \pm 0.9(0.99)$ & $28.3 \pm 1.4(0.99)$ & $29.6 \pm 1.8(0.99)$ \\
\hline $\mathbf{C} 3 \dagger$ & $40.9 \pm 3.9(0.97)$ & $34.2 \pm 1.7(0.99)$ & $36.5 \pm 2.6(0.99)$ \\
\hline $\mathbf{C 4} \dagger$ & $37.4 \pm 3.9(0.97)$ & $45.6 \pm 11.8(0.82)$ & $48.0 \pm 11.5(0.85)$ \\
\hline Average & $41.2 \pm 3.0$ & $37.9 \pm 8.1$ & $38.9 \pm 7.8$ \\
\hline
\end{tabular}

$\dagger \mathrm{C} 1, \mathrm{C} 2, \mathrm{C} 3$, and $\mathrm{C} 4$ are $3.31,34.35,56.01$ and $142.70 \mathrm{mg} \mathrm{kg}^{-1}$ for MITC; 0.60, 9.55, 14.18, and $58.82 \mathrm{mg} \mathrm{kg}^{-1}$ for the (E)-1,3-D isomer; and 0.65, 9.98, 15.27 , and $60.33 \mathrm{mg} \mathrm{kg}^{-1}$ for the $(Z)-1,3-D$ isomer, respectively.

$\$$ Mean \pm standard error. Data in parentheses are coefficients of fitting (adjusted $r^{2}$ ).

tions $(P<0.05)$ (Table 4$)$. The average activation energy for MITC was $46.21 \mathrm{~kJ} \mathrm{~mol}^{-1}$, which is consistent with a previous report (Gan et al., 1999). At each initial concentration, the overall $k_{1}$ increased $\sim 2$ times with every $10^{\circ} \mathrm{C}$ increase between 20 and $40^{\circ} \mathrm{C}$ (Table 1 ). Thus, biodegradation of MITC was not significantly suppressed at $40^{\circ} \mathrm{C}$. When $k_{0.5}$ is used to evaluate MITC degradation as affected by temperature, the calculated activation energy was not significantly different among different initial concentrations $(P>0.05)$ (Table 4), with an average of $41.20 \mathrm{~kJ} \mathrm{~mol}^{-1}$. This value was not statistically different from that calculated using $k_{1}$ (46.21 $\left.\mathrm{kJ} \mathrm{mol}^{-1}\right)(P>0.05)$.

Degradation of 1,3-D isomers between 20 and $40^{\circ} \mathrm{C}$ can also be described by the Arrhenius equation $\left(r^{2}>\right.$ 0.82 ) (Table 4). There was no significant difference in activation energy for both isomers at different initial concentrations except at the highest concentration at which the activation energy was significantly greater than that at other concentrations $(P<0.05)$ (Table 4$)$. The average activation energy for $(E)-1,3-\mathrm{D}(52.3 \mathrm{~kJ}$ $\mathrm{mol}^{-1}$ ) over the four initial concentrations was not significantly different from that of the $(Z)-1,3-\mathrm{D}(59.3 \mathrm{~kJ}$ $\left.\mathrm{mol}^{-1}\right)(P>0.05)$. When $k_{0.5}$ was applied to calculate activation energy, the resulting values for both isomers were significantly different among different initial concentrations $(P<0.05)$. However, the average value for the $(E)$-isomer $\left(37.86 \mathrm{~kJ} \mathrm{~mol}^{-1}\right)$ at four initial concentrations was not statistically different from that of the $(Z)$-isomer $\left(38.95 \mathrm{~kJ} \mathrm{~mol}^{-1}\right)$. For either isomer, the average activation energy calculated by $k_{0.5}$ was significantly smaller than that calculated by $k_{1}(P<0.05)$.

\section{CONCLUSIONS}

The degradation of MITC and 1,3-D isomers at each of the four initial concentrations was adequately described by first-order and half-order kinetics, but not by second-order kinetics and the Michalies-Menten model. However, the dependence of the derived first-order and half-order degradation rate constants on initial concentration makes it invalid to use first-order and half-order kinetics to describe the degradation. Overall, none of the models tested satisfactorily described degradation of MITC and 1,3-D isomers over the range of initial concentrations. This raises a serious question as to the validity of first-order kinetics for representing fumigant degradation in soils at different initial concentrations. This problem tends to be overlooked since the firstorder degradation rate constant is usually obtained at one initial concentration. Thus, the concentration effect as observed in this study is ignored. Even worse, the derived first-order degradation rate constant at one initial concentration is often used in integrated simulation models for predicting chemical fate and dissipation.

Comparisons of fumigant degradation in sterilized and nonsterilized soils revealed that microbial degradation was the major dissipation pathway for all fumigants, although microbial degradation was more involved in degrading MITC than in degrading 1,3-D isomers. Analyses of MITC degradation at high and low initial concentrations in sterilized and nonsterilized soils demonstrated that the reduced MITC degradation rate constant at high concentration may have resulted from the inhibitory effects of the fumigant on degrading microorganisms. The overall degradation rate constants of MITC and 1,3-D isomers changed exponentially with temperature and followed the empirical Arrehnius equation between 20 and $40^{\circ} \mathrm{C}$.

\section{ACKNOWLEDGMENTS}

We thank Q. Zhang for her assistance in obtaining some of the experimental data. This study was funded by USDANational Research Initiative Grant \#98-35316-6450.

\section{REFERENCES}

Alexander, M., and K.M. Scow. 1989. Kinetics of biodegradation in soil. p. 243-269. In B.L. Sawhney and K. Brown (ed.) Reactions and movement of organic chemicals in soils. SSSA Spec. Publ. 22. SSSA, Madison, WI. 
Boesten, J.J.T.I., and A.M.A. van der Linden. 1991. Modeling the influences of sorption and transformation on pesticide leaching and persistence. J. Environ. Qual. 20:425-435.

Gan, J., S.K. Papiernik, S.R. Yates, and W.A. Jury. 1999. Temperature and moisture effects on fumigant degradation in soil. J. Environ. Qual. 28:1436-1441.

Grover, R., J.D. Wolt, A.J. Cessna, and H.B. Schiefer. 1997. Environmental fate of trifluralin. Rev. Environ. Contam. Toxicol. 153:1-64.

Hamaker, J.W. 1972. Decomposition: Quantitative aspects. p. 253340. In C.A.I. Goring and J.W. Hamaker (ed.) Organic chemicals in the soil environment. Marcel Dekker, New York.

Hamaker, J.W., and C.A.I. Goring. 1976. Turnover of pesticide residues in soil. p. 219-243. In D.D. Kaufman (ed.) Bound and conjugated pesticide residues. ACS Symp. Ser. 29. Am. Chem. Soc., Washington, DC.

Hamaker, J.W., C.R. Youngson, and C.A.I. Goring. 1968. Rate of detoxification of 4-amino-3,5,6-trichloropicolinic acid in soil. Weed Res. 8:46-57.

Hance, R.J., and C.E. McKone. 1971. Effect of concentration on the decomposition rates in soil of atrazine, linuron and picloram. Pestic. Sci. 2:31-34.

Helweg, A.R. 1975. Degradation of ${ }^{14} \mathrm{C}$-labelled maleic hydrazide in soil as influenced by sterilization, concentration and pretreatment. Weed Res. 15:53-58.

Hill, B.D., and G.B. Schaalje. 1985. A two-compartment model for the dissipation of deltamethrin on soil. J. Agric. Food Chem. 33:10011006.

Kearney, P.C., and R.D. Wauchope. 1998. Disposal options based on properties of pesticides in soil and water. p. 35-57. In P.C. Kearney and T. Roberts (ed.) Pesticide remediation in soils and water. John Wiley \& Sons, New York.
Ladd, J.N., P.G. Brisbane, J.H.A. Butler, and M. Amato. 1976. Studies on soil fumigation. III. Effects in enzyme activities, bacterial numbers and extractable ninhydrin reactive compounds. Soil Biol. Biochem. 8:255-260.

Macalady, J.L., M.E. Fuller, and K.M. Scow. 1998. Effects of metam sodium fumigation on soil microbial activity and community structure. J. Environ. Qual. 27:54-63.

Parr, J.F. 1974. Effects of pesticides on microorganisms in soil and water. p. 315-340. In W.D. Guenzi (ed.) Pesticides in soil and water. SSSA, Madison, WI.

Reffstrup, T.K., H. Sorensen, and A. Helweg. 1998. Degradation of mecoprop at different concentrations in surface and sub-surface soil. Pestic. Sci. 52:126-132.

Schmidt, S.K., S. Simkins, and M. Alexander. 1985. Models for the kinetics of biodegradation of organic compounds not supporting growth. Appl. Environ. Microbiol. 50:323-331.

Smelt, J.H., S.J.H. Crum, and W. Teunissen. 1989. Accelerated transformation of the fumigant methyl isothiocyanate in soil after repested application of metam-sodium. Environ. Sci. Health B 24: 437-455.

Soulas, G. 1982. Mathematical model for microbial degradation of pesticides in the soil. Soil Biol. Biochem. 14:107-115.

Sparks, D.L. 1989. Kinetics of soil chemical processes. Academic Press, San Diego, CA.

Tu, C.M. 1972. Effect of four nematocides on activities of microorganisms in soil. Appl. Microbiol. 23:398-401.

Walker, A. 1978. Simulation of the persistence of eight soil-applied herbicides. Weed Res. 18:305-313.

Wolt, J. 1997. Environmental fate of trifluralin. Rev. Environ. Contam. Toxicol. 153:65-90.

\title{
Organochlorine Pollutants in Remote Mountain Lake Waters
}

\author{
Rosa Vilanova, Pilar Fernández, Carolina Martínez, and Joan O. Grimalt*
}

\begin{abstract}
Hexachlorocyclohexanes (HCHs; $\alpha$ - and $\gamma$-isomers), endosulfans ( $\alpha$ - and $\beta$-isomers and the sulfate residue), hexachlorobenzene (HCB), dichlorodiphenyltrichloroethane (DDTs), and polychlorobiphenyls (PCBs) were measured in waters from three European remote mountain lakes situated in the Alps, Pyrenees, and Caledonian mountains. Sampling encompassed both ice-free and ice-covered periods at different water column depths. High $\mathrm{HCH}$ concentrations were found in all lakes, those in the Alps and Pyrenees (990-2900 pg/L) being among the highest recorded in continental waters. Endosulfans and endosulfan sulfate (120-1150 pg/L) were the second major group of organochlorine contaminants, showing a remarkable stability upon atmospheric long-range transport. The concentrations of HCB, DDTs, and PCB (4-8, 0.6-16, and 26-110 pg/L, respectively) were low in comparison with other continental waters. Hexachlorocyclohexanes, endosulfans, and HCB were essentially found in the dissolved phase. Phase partitioning of the more hydrophobic compounds exhibited a dependence on temperature and water-suspended particles. Comparison between different sampling seasons and water depths indicated a remarkable concentration uniformity within lake, but major interlake differences. Normalization to turnover rates showed higher interlake similarity. Preferential accumulation of the less volatile compounds in the Alp lake and significant increase of baseline contributions of organochlorine compounds and residues in the Caledonian lake are also evidenced from these turnover rates.
\end{abstract}

Department of Environmental Chemistry, Institute of Chemical and Environmental Research (CSIC), Jordi Girona, 18-26. 08034 Barcelona, Catalonia, Spain. Received 14 July 2000. *Corresponding author (jgoqam@cid.csic.es).

Published in J. Environ. Qual. 30:1286-1295 (2001).
$\Delta$ LaRge number of persistent organic pollutants A(POPs) are organochlorine compounds (OCs) (United Nations Economic Commission for Europe, 2000). High mountain lakes are some of the remote areas under potential stress by POPs. These lakes can be defined as those situated above the timberline receiving their waters through atmospheric fallout. Their ecological and environmental value is high because they often support unique species of plant and animal communities. They are often the headwater catchments of water supplies and excellent sensors of environmental change for entire mountain environments.

Most OC studies in lacustrine waters have been developed in large lakes, such as the Great Lakes in the United States and Canada (Oliver and Niimi, 1988; Jeremiason et al., 1994; Pearson et al., 1996; Swackhamer et al., 1988), Lake Baikal in Russia (Kucklick et al., 1994; Iwata et al., 1995), and some lakes in the Arctic (Kidd et al., 1998). Very few studies have been concerned with high-altitude mountain lakes (e.g., USA [Datta et al., 1998] and India [Dua et al., 1998]). Not one of these studies has been conducted in Europe. The lakes in the mountain regions of Europe constitute the most remote and least disturbed inland environments and these lakes are especially sensitive to airborne pollutant deposition, because their catchments have only

Abbreviations: DDT, dichlorodiphenyltrichloroethane; $\mathrm{HCB}$, hexachlorobenzene; $\mathrm{HCH}$, hexachlorocyclohexane; OC, organochlorine compound; PCB, polychlorobiphenyls. 